\title{
Fiber-reinforced Composite Space Maintainers: A Literature Review of their Survival Rate
}

\author{
Mohammed S. Aldossary, Aref M. Althobity, Nader A. Assal, Moath I. Alfraih
}

\section{ABSTRACT}

Premature loss of posterior primary teeth necessitates space maintaining to prevent space loss and compromising the dentition. Conventional stainless steel band-and-loop space maintainer (BL-SM) is a non-invasive device commonly used to maintain space after the early loss of a single deciduous tooth until the permanent tooth erupts. However, these devices require laboratory work, consume time, and are relatively expensive. Clinically, they tend to fracture, bend or debond under occlusal forces, and they are not considered esthetic.

Thus, alternatives to the BL-SM have been investigated. The fiberreinforced composite space maintainer (FRC-SM) has various advantages and has been suggested as an alternative to the BL-SM.

The aim of this review is to explore the survival rate of FRC-SM reported in the literature. We have found a wide variation in the reported results, with promising results shown for FRC-SM, especially over short periods. Therefore, longer follow-up periods, placement techniques and clinical effectiveness with respect to this type of space maintainer need to be further evaluated.

Keywords: Space maintainer, Band-and-loop, Fiber-reinforced composite, Survival rate, Longevity.

\section{INTRODUCTION}

Early loss of a posterior primary tooth would result in space loss and compromised dentition [1]. The placement of an effective space maintainer upon premature tooth loss could reduce future occlusal discrepancies such as malocclusion [2].

The conventional stainless steel band-and-loop space maintainer (BL-SM) is a non-invasive fixed device that is commonly used for such a purpose [3]. It was reported that the survival rate of BL-SMs, in many cases, is often low and insufficient time for the permanent tooth to erupt [4], [5]. Common reasons for the failure of these BL-SMs include fracturing, bending, or debonding of their components under occlusal forces [1], [4].

These obvious limitations and challenges warrant the investigation of new materials and device designs for the treatment of premature single tooth loss. Fiber-reinforcedcomposite resin material is known for its flexural and physical strength [6], [7]. The fiber-reinforced composite space maintainer (FRC-SM) has been suggested as an alternative to the conventional stainless steel BL-SM [6][8].

This article will review the relevant literature presenting
Published Online: September 11, 2020

ISSN: $2684-4443$

DOI : 10.24018/ejdent.2020.1.5.22

Mohammed S. Aldossary* Specialist in Pediatric Dentistry, General Directorate of Dentistry, Ministry of Health, Riyadh, Saudi Arabia.

(e-mail: msfd99@hotmail.com) Aref M. Althobity

General Dentist, General Directorate of Dentistry, Ministry of Health, Riyadh, Saudi Arabia.

(e-mail: arifth@yahoo.com)

Nader A. Assal

Specialist in Dental Public Health,

General Directorate of Dentistry, Ministry of Health, Riyadh, Saudi Arabia.

(e-mail: drnaderassal@gmail.com) Moath I. Alfraih

General Dentist, General Directorate of Dentistry, Ministry of Health, Riyadh, Saudi Arabia.

(e-mail: dr.alfraih@gmail.com)

*Corresponding Author

an overview of the basic rationale for space maintenance, the conventional BL-SM, the FRC-SM, the clinical survival rates and reasons for failure.

\section{THE FUNDAMENTAL RATIONALE FOR SPACE MAINTENANCE}

A primary tooth's premature loss usually contributes to space loss due to tilting, drifting, and/or rotation of the mesial teeth, and distal to the edentulous site [9]. Potential consequences of space loss include impaction of un-erupted permanent teeth, dental arch midline shift, and over-eruption of opposing teeth, all of which can lead to malocclusion and impairment of oral functions such as speech and mastication [2]. Therefore, placing a space maintaining device would stabilize the arch dimensions and reduce or eliminate these undesirable consequences. Additionally, it can help prevent the need for future extensive fixed orthodontic treatment in mild to moderate crowding cases [1].

On the other hand, when assessing if a space maintainer is needed, it is very important to consider the clinical situation and multiple factors for each case [1], [2], [10]. These considerations are presented in the American Academy of Pediatric Dentistry (AAPD) guidelines [10]. 


\section{THE BAND-AND-LOOP SPACE MAINTAINER (BL-SM)}

Currently, the most commonly used fixed space maintainer is the conventional stainless steel BL-SM [1], [3]. Although the fabrication of a BL-SM is relatively simple, achieving a good fit of the band around the anchor tooth is sometimes difficult. Additionally, patients often experience discomfort in the surrounding soft tissue during the band fitting process, which might necessitate local anesthesia [1], [8]. A poor fitting BL-SM leads to a delay in the final placement of the appliance, as a new impression must be made and submitted to the laboratory where either the existing BL-SM is being corrected or a new BL-SM is being produced. The BL-SM fabrication is labor- and timeintensive and require several materials which contribute to additional cost inflation [6].

With regard to the BL-SM failure, the key reasons were cement failure, solder breakage, and the emergence of soft tissue lesions associated with the devices [4], [5]. Another common cause of BL-SM failure is bending of the metal loops and embedding in the gingival tissues, leading to gingival irritation or overgrowth [5]. Fracture, bending or dislodgement of BL-SM loops cannot be repaired chairside; hence, the space maintainer must be removed and refabricated in a dental laboratory, leading to additional time and cost [5].

A further disadvantage is that stainless steel BL-SMs are not esthetically pleasing and may pose a risk of metal allergy in susceptible individuals. Furthermore, BL-SMs are associated with plaque accumulation, gingival inflammation, bacterial colonization and possible periodontal destruction [1].

Commercially available alternatives to the BL-SM include devices that eliminate the laboratory process by supplying prefabricated loops that can be fitted to the band chairside. One example is "the Denovo Pediatric Chairside Space Maintainer System" (Denovo Dental, Inc., CA, USA). However, such devices are not appropriate for all clinical circumstances, and the above-mentioned problems also apply to these space maintainers [6].

The apparent drawbacks and problems associated with BL-SM warrant research into new materials and product designs for premature tooth loss treatment [1].

\section{THE FIBER-REINFORCED COMPOSITE SPACE MAINTAINER (FRC-SM)}

Fiber-reinforced composite (FRC) applications in dentistry seem generally promising. More specifically, there is growing recognition of the capacity of FRC as the material basis of space maintainers [6], [7].

The FRC-SM has several advantages over the BL-SM. It has greater esthetic appeal compared to stainless steel, is minimally invasive, does not impinge on soft tissue, is easily removable, and more readily accepted by pediatric patients [1], [4]. The FRC-SM exhibits high durability and is comparable in physical strength to the stainless steel BL-SM [6].

Fabricating and fitting an FRC-SM is relatively economical, as no impression materials or orthodontic bands are required, and laboratory services and costs are avoided
[6]. The FRC-SM has a simple design that can be placed in a single appointment, and its placement is quicker because the composite used cures on demand [1], [7].

Furthermore, an FRC-SM can be repaired chairside without requiring the services of a laboratory and still maintain its original physical strength [6].

Because bending of the FRC-SM under occlusal forces is limited, the device does not impinge on or cause trauma to underlying soft tissue [7].

On the other hand, it is well known that composite materials are technique sensitive; hence, moisture must be controlled when placing the FRC-SM. Similar to the BL$\mathrm{SM}$, the FRC-SM neither prevents over-eruption of the opposing tooth, nor restores function of the missing tooth [6], [7]. However, these challenges can be overcome by placing a pontic in the FRC-SM space maintainer but not the BL-SM.

\section{CLINICAL STUDIES ON FRC-SMS AND THEIR SURVIVAL RATE}

Several clinical studies have assessed the FRC-SMs only [11]-[14], or in comparison to BL-SMs [15]-[17]. In one study, the FRC-SM was compared to both band-and-loop and direct bonded space maintainers [18]. The summary of the included studies is presented in Table 1. The survival rates and mean survival durations are presented in Table 2.

TABLE 1: SUMMARY OF THE INCLUDED STUdIES AVAILABLE IN THE LITERATURE

\begin{tabular}{|c|c|c|c|}
\hline Comparison & Study & Sample & Follow up \\
\hline \multirow{4}{*}{$\begin{array}{l}\text { FRC-SM } \\
\text { Only }\end{array}$} & $\begin{array}{l}\text { Kirzioglu \& } \\
\text { Erturk, } 2004\end{array}$ & $\begin{array}{l}29 \text { children } \\
\text { 40 FRC-SMs }\end{array}$ & $\begin{array}{l}\text { Up to } 12 \\
\text { months }\end{array}$ \\
\hline & $\begin{array}{l}\text { Kargul et al., } \\
\quad 2005\end{array}$ & $\begin{array}{l}23 \text { FRCR in } 19 \\
\text { Children } \\
\text { Only FRC-SM } \\
\end{array}$ & $\begin{array}{l}\text { Only at } 12 \\
\text { months }\end{array}$ \\
\hline & $\begin{array}{l}\text { Saravanakumar } \\
\text { et al., } 2013\end{array}$ & $\begin{array}{c}30 \text { children } \\
\text { Only FRC-SM }\end{array}$ & $\begin{array}{l}\text { Up to } 18 \\
\text { months }\end{array}$ \\
\hline & $\begin{array}{l}\text { Kirzioglu et al., } \\
2017\end{array}$ & $\begin{array}{c}44 \text { children } \\
\text { Only FRC-SM }\end{array}$ & $\begin{array}{l}\text { Clinical \& } \\
\text { radiographic. } \\
\text { Up to } 24 \\
\text { months }\end{array}$ \\
\hline \multirow{3}{*}{$\begin{array}{c}\text { FRC-SM vs } \\
\text { BL-SM }\end{array}$} & $\begin{array}{c}\text { Subramaniam et } \\
\text { al., } 2008\end{array}$ & $\begin{array}{c}30 \text { children } \\
\text { FRC-SM vs BL-SM } \\
\text { Split mouth }\end{array}$ & $\begin{array}{l}\text { Up to } 12 \\
\text { months }\end{array}$ \\
\hline & $\begin{array}{l}\text { Nidhi et al., } \\
2012\end{array}$ & $\begin{array}{c}20 \text { children } \\
\text { FRC-SM vs BL-SM } \\
\text { Split mouth }\end{array}$ & $\begin{array}{l}\text { At } 1,3,5 \\
\text { months }\end{array}$ \\
\hline & $\begin{array}{l}\text { Garg et al., } \\
\quad 2014\end{array}$ & $\begin{array}{c}30 \text { children } \\
\text { FRC-SM vs BL-SM } \\
\text { Split mouth }\end{array}$ & $\begin{array}{l}\text { At } 1,3,6 \\
\text { months }\end{array}$ \\
\hline $\begin{array}{c}\text { FRC-SM vs } \\
\text { BL-SM vs } \\
\text { direct bonded }\end{array}$ & $\begin{array}{l}\text { Tunc et al., } \\
2012\end{array}$ & $\begin{array}{c}30 \text { children } \\
\text { FRC-SM vs BL-SM } \\
v s \text { direct bonded } \\
10 \text { each }\end{array}$ & $\begin{array}{l}\text { Up to } 12 \\
\text { months }\end{array}$ \\
\hline
\end{tabular}

The survival period of FRC-SMs has been reported in the literature to be in the range of 5 to 14.8 months [12], [14]. The survival rate of FRC-SMs over a 6-month period ranged from $27 \%$ to $97.7 \%$, and a 12 -month period ranged from $6 \%$ to $86.4 \%$ [11], [14]. These wide variations may be due to the influence of different techniques or designs, different materials employed, and different research methodologies in the various studies. It seems that the type of fiber selected 
may play a significant role in determining the success of an FRC-SM [6]. Glass fibers may be preferable to polyethylene fibers for the purposes of FRC-SM construction. This needs to be researched further [6].

TABLE 2: SUMMARY OF THE FRC-SM SURVIVAL FINDINGS

\begin{tabular}{|c|c|c|c|c|c|}
\hline \multirow{2}{*}{ Study } & \multicolumn{4}{|c|}{ Kaplan-Meier survival rate (\%) } & \multirow{2}{*}{$\begin{array}{c}\text { Mean } \\
\text { duration } \\
\text { (months) }\end{array}$} \\
\hline & $\begin{array}{c}6 \\
\text { months }\end{array}$ & $\begin{array}{c}12 \\
\text { months }\end{array}$ & $\begin{array}{c}18 \\
\text { months }\end{array}$ & $\begin{array}{c}24 \\
\text { months }\end{array}$ & \\
\hline $\begin{array}{l}\text { Kirzioglu \& } \\
\text { Erturk, } 2004\end{array}$ & $27 \%$ & $6 \%$ & & & 5.7 \\
\hline $\begin{array}{l}\text { Kargul et al., } \\
\quad 2005\end{array}$ & & $43 \%$ & & & 5 \\
\hline $\begin{array}{l}\text { Saravanakumar } \\
\text { et al., } 2013\end{array}$ & $84 \%$ & $47 \%$ & $13 \%$ & & 12 \\
\hline $\begin{array}{c}\text { Kirzioglu et } \\
\text { al., } 2017\end{array}$ & $97.7 \%$ & $86.4 \%$ & $63.6 \%$ & $52.3 \%$ & 14.8 \\
\hline $\begin{array}{l}\text { Subramaniam } \\
\text { et al., } 2008\end{array}$ & $\begin{array}{l}66.7 \% \\
\text { (BL-SM } \\
43.3 \%)\end{array}$ & $\begin{array}{l}53.3 \% \\
\text { (BL-SM } \\
33.3 \%)\end{array}$ & & & - \\
\hline $\begin{array}{l}\text { Nidhi et al., } \\
2012\end{array}$ & $\begin{array}{c}79 \% \\
(\mathrm{BL}-\mathrm{SM} \\
63 \%) \\
\end{array}$ & & & & - \\
\hline $\begin{array}{c}\text { Garg et al., } \\
2014\end{array}$ & $\begin{array}{l}63.3 \% \\
\text { (BL-SM } \\
36.7 \%) \\
\end{array}$ & & & & - \\
\hline $\begin{array}{c}\text { Tunc et al., } \\
2012\end{array}$ & $\begin{array}{c}40 \% \\
\text { (BL-SM } \\
100 \%)\end{array}$ & $\begin{array}{c}20 \% \\
\text { (BL-SM } \\
90 \%)\end{array}$ & & & 6.7 \\
\hline
\end{tabular}

Most authors of the included studies concluded that the FRC-SM could be a viable alternative to the BL-SM. Nonetheless, more work regarding the placement technique has been recommended because FRC-SM designs and placement methods have not been standardized yet.

Kirzioglu \& Erturk [11], conducted a study in which they placed 40 FRC-SMs with a single Splint-it glass fiber (Jeneric/Pentron) bonded to the lingual/ palatal surfaces of two anchor (abutment) teeth. No rubber dam was used during the placement of the space maintainers. This study found the least survival rate of FRC-SMs at 6-month, and 12 -month recalls $(27 \%$, and $6 \%$ respectively). The 40 FRCSMs were placed in 29 children with a mean age of 10.1 years, which was the older sample among the included studies; hence, this could impact on the survival rate of the FRC-SMs [11].

In 2005, Kargul et al. [12], reported 23 FRC-SMs that were placed in 19 children, using EverStick glass fibers (Stick Tech). In their study, both single and double edentulous areas were included in this study. No rubber dam was used during placement. EverStick is a semimanufactured product made of glass fibers, thermoplastic polymer, and light-curing resin matrix for reinforcing the dental polymer. Clinical advantages of EverStick include: (1) cost and time savings; (2) no need for a cast model; (3) no second visit; (4) easy to apply; (5) reliable adhesive bonding; (6) no metal allergy; (7) easy to clean; (8) natural feel; and (9) esthetically desirable. They reported the survival rate at 12 -month recall only, which was $43 \%$, with a mean duration of 5 months. The difference between survived and failed FRC-SMs was not statistically significant. Moreover, they found longer survival periods for devices placed in the maxilla than for those placed in the mandible [12]. This could be explained as occlusal trauma is more prevalent in the mandible than in the maxilla [1], [4]. Additionally, they found that FRC-SMs for one tooth lost survived longer than those for two teeth lost [12].

Saravanakumar et al. [13], assessed the FRC-SMs placed in 30 children up to 18 months. The survival rates were $47 \%$ and $13 \%$ at 12 -month and 18-month, respectively, with a mean duration of 12 months. The FRC-SMs placed in the maxillary arch showed higher survival than those placed in the mandible [13].

More recently, Kirzioglu et al. [14], investigated 44 FRCSMs placed in children for missing primary molars, with clinical and radiographic follow-up up to 24 months. The mean duration was 14.8 months, with survival rates of $86.4 \%$ and $52.3 \%$ at 12-month and 24-month recalls, respectively. About $32 \%$ of the FRC-SMs were removed as permanent teeth erupted. Interestingly, they found no significant association between survival time and "gender, localization, and measured space" [14].

On the other hand, with regards to comparison of the FRC-SM to other SMs, Subramaniam et al. [15], conducted a study comparing the FRC-SM with the BL-SM in 30 children (split-mouth design) up to 12 months. The technique employed for the placement of each FRC-SM involved the bonding of a single glass fiber (Stick Tech) between the two abutment teeth adjacent to the premature extraction space. The authors found that $66.7 \%$ of the FRCSMs had survived after 6 months, and $53.3 \%$ had survived after 12 months. On the other hand, regarding the BL-SMs, survival rates of $43.3 \%$ and $33.3 \%$ were reported after 6 and 12 months, respectively. Although the FRC-SMs showed a higher survival rate, this was not statistically significant. Furthermore, the authors reported less trauma to the gingiva with FRC-SMs compared with BL-SMs [15].

In 2014, Garg et al. [16], compared the performance of the FRC-SM with the BL-SM in 30 children (split-mouth design). For single tooth loss only, these space maintainers were designed to have two separate fibers bonded to the lingual and buccal aspects of two anchor teeth adjacent to the edentulous area. They were constructed using Ribbond polyethylene fibers (Ribbond) [19] and placed under the rubber dam. They only followed up the cases at 1,3 , and 6 months. After 6 months, a survival rate of $63.3 \%$ was reported for the FRC-SMs, and a survival rate of $36.7 \%$ was reported for the BL-SMs. The authors recommended that the FRC-SM be considered as a favorable alternative to the BLSM based on the lower failure rate and quick placement time of the FRCSM, along with the fact that patients more readily accepted the FRCSM [16].

Unfortunately, it was not specified in the studies by Subramaniam et al. [15], and Garg et al. [16], whether fibers were bonded to deciduous or permanent teeth. The focus of these studies was the premature loss of deciduous teeth, rather than the teeth used to anchor the FRC-SMs. This important concern needs to be considered when comparing the results of the studies in the literature.

The ideal FRC-SM should be successful, irrespective of whether it is bonded to a permanent or a deciduous tooth. Bond strength to deciduous enamel is, however, lower than bond strength to permanent enamel [20], especially if the deciduous tooth enamel is demineralized [21]. The study by 
Kirzioglu \& Erturk [11], found higher failure rate when primary teeth were used as abutments.

Nidhi et al. [17], compared FRC-SMs with BL-SMs in 20 children (split-mouth design) for only five months. Although the FRC-SMs showed higher survival (79\%) than the BL-SMs (63\%), the difference was not significant [17].

Tunc et al. [18], compared the effectiveness of three SMs; FRC-SM, BL-SM, and direct bonded SM placed in 30 children (10 each), up to 12 months or failure of devices. In contrast to other studies, they found the survival rate of BLSMs was the best (100\% at 6-month, and $90 \%$ at 12 -month), with a survival period of 11.2 months. The FRC-SMs showed the worst survival rate $(40 \%$ at 6 -month, and $20 \%$ at 12-month), with a survival period of 6.7 months. Furthermore, age, gender, dental arch, and side of the jaw were not significantly correlated with the survival rate of SMs [18].

\section{REASONS FOR FRC-SM FAILURES}

Most studies found similar results regarding the reasons for the failure of FRC-SMs. The most reason for failure of FRC-SMs was debonding, either on the enamel-composite or on the fiber-composite interfaces, which indicates FRCSM bond strength, as well as placement technique, require enhancement [11], [15], [16].

The breakdown of the enamel-composite interface was reported to be more than debonding at the fiber-composite interface [11], [15], [16]. The breakdown of the enamelcomposite interface is attributed to a relatively weak bond between composites and the aprismatic enamel of deciduous teeth [15], [16].

Kirzioglu \& Erturk [11], reported that the enamelcomposite interface broke down within just one month when fibers were placed without a rubber dam. This emphasizes the importance of moisture control during FRC-SM placement to ensure good bond strength and increase the likelihood of ultimate device success.

On the other hand, debonding at the fiber-composite interface may be due to the strain placed on the fibercomposite bond during finishing, placement of the fiber in the bite, and/or wearing of the composite layer by the forces of mastication [11], [15], [16]. As FRC-SM-related techniques are not yet standardized, differences in bonding agents, placement techniques, types of composite used and operator skill make it difficult to compare these results and may contribute to the varied results reported in the literature [12], [15], [16].

A second prevalent reason for the failure of FRC-SMs was fracturing of the fiber frame [15,] [16]. Fiber frames are thought to fracture due to mechanical stresses arising from the chewing of hard/sticky foods, and/or due to the overeruption of the tooth opposing the edentulous area, which subsequently increases and concentrates the masticatory forces on the fiber [15], [16].

The effects of masticatory forces and the degree of clearance between the fiber and the opposing tooth, especially when the fiber is bonded to the functional side of an abutment tooth, should be taken into consideration during the placement of a FRC-SM [4].

\section{LIMITATIONS OF CURRENT EVIDENCE AND RECOMMENDATIONS FOR FUTURE RESEARCH}

The sample size of the available studies in the literature ranged from 10 to 44 devices, for relatively short period of follow-up. Further research based on a larger sample size and a longer follow-up period would be necessary before the FRC-SM could be confidently recommended as a reliable alternative to the BL-SM.

It would also be good to investigate and compare the FRCSM's effectiveness when bonded to primary or permanent teeth, and the influence of using different FRC-SM materials or placement techniques on overall device success.

We also recommend that further research be done on whether this device would prove more successful if mechanical retention were enhanced when bonding FRCSMs to deciduous tooth enamel.

\section{CONCLUSIONS}

Using FRC-SMs instead of lab-constructed BL-SMs would be more economical, making space maintenance more accessible. This will be beneficial, especially for children in rural areas where dental laboratory services are not available.

Studies indicate that the main cause of FRC-SM failure was debonding, which suggests that it is necessary to work on techniques to improve bond strength, especially to deciduous anchor teeth.

The FRC-SM cannot yet be confidently recommended as a reliable alternative to the BL-SM, and the relatively short survival period indicates the need for improvement of the FRC-SM.

Longer follow-up periods, placement techniques and clinical effectiveness with respect to this type of space maintainer need to be further evaluated.

\section{REFERENCES}

[1] Ahmad AJ, Parekh S, Ashley PF. Methods of space maintenance for premature loss of a primary molar: a review. Eur Arch Paediatr Dent. 2018;19(5):311-320. doi:10.1007/s40368-018-0357-5

[2] Simon T, Nwabueze I, Oueis H, Stenger J. Space maintenance in the primary and mixed dentitions. J Mich Dent Assoc. 2012;94(1):38-40.

[3] Watt E, Ahmad A, Adamji R, Katsimbali A, Ashley P, Noar J. Space maintainers in the primary and mixed dentition--a clinical guide. $\mathrm{Br}$ Dent J. 2018;225(4):293-298.

[4] Ramakrishnan M, Dhanalakshmi R, Subramanian EMG. Survival rate of different fixed posterior space maintainers used in Paediatric Dentistry - A systematic review. Saudi Dent J. 2019;31(2):165-172. doi:10.1016/j.sdentj.2019.02.037

[5] Sasa IS, Hasan AA, Qudeimat MA. Longevity of band and loop space maintainers using glass ionomer cement: a prospective study. Eur Arch Paediatr Dent. 2009;10(1):6-10.

[6] Kulkarni G, Lau D, Hafezi S. Development and testing of fiberreinforced composite space maintainers. J Dent Child 2009;76(3):204-208.

[7] Yeluri R, Munshi AK. Fiber reinforced composite loop space maintainer: An alternative to the conventional band and loop. Contemp Clin Dent. 2012;3(Suppl1):26-28.

[8] Deshpande SS, Bendgude VD, Kokkali V V. Survival of Bonded Space Maintainers: A Systematic Review. Int J Clin Pediatr Dent 2018;11(5):440-445.

[9] Tunison W, Flores-Mir C, ElBadrawy H, Nassar U, El-Bialy T. Dental arch space changes following premature loss of primary first molars: a systematic review. Pediatr Dent. 2008;30(4):297-302.

[10] AAPD. Management of the developing dentition and occlusion in pediatric dentistry. Pediatr Dent. 2017;39(6):334-347.

[11] Kirzioglu Z, Ozay Erturk MS. Success of reinforced fiber material space maintainers. J Dent Child. 2004;71(2):158-162. 
[12] Kargul B, Caglar E, Kabalay U. Glass fiber-reinforced composite resin as fixed space maintainers in children: 12-month clinical follow-up. J Dent Child. 2005;72(3):109-112.

[13] Saravanakumar MS, Siddaramayya J, Sajjanar AB, Godhi BS, Reddy NS, Krishnam RP. Fiber technology in space maintainer: A clinical follow-up study. J Contemp Dent Pract. 2013;14(6):1070-1075.

[14] Kirzioglu Z, Çiftçi ZZ, Yetis CÇ. Clinical Success of Fiberreinforced Composite Resin as a Space Maintainer. J Contemp Dent Pract. 2017;18(3):188-193.

[15] Subramaniam P, Babu GKL, Sunny R, others. Glass fiber-reinforced composite resin as a space maintainer: A clinical study. J Indian Soc Pedod Prev Dent. 2008;26(7):98-103.

[16] Garg A, Samadi F, Jaiswal JN, Saha S, others. "Metal to resin": A comparative evaluation of conventional band and loop space maintainer with the fiber reinforced composite resin space maintainer in children. J Indian Soc Pedod Prev Dent. 2014;32(2):111-116.

[17] Nidhi C, Jain RL, Neeraj M, Harsimrat K, Samriti B, Anuj C. Evaluation of the clinical efficacy of glass fiber reinforced composite resin as a space maintainer and its comparison with the conventional band and loop space maintainer. An in vivo study. Minerva Stomatol. 2012;61(1-2):21-30.

[18] Tunc E Sen, Bayrak S, Tuloglu N, Egilmez T, Isci D. Evaluation of survival of 3 different fixed space maintainers. Pediatr Dent. 2012;34(4):97-102.

[19] Kallar S, Brar GS. Ribbond as an esthetic space maintainer. Int J Med Dent Sci. 2012;1(2):15-19.

[20] Peutzfeldt A, Nielsen LA. Bond strength of a sealant to primary and permanent enamel: phosphoric acid versus self-etching adhesive. Pediatr Dent. 2004;26(3):240-244.

[21] Tedesco TK, Maxnuck Soares FZ, Miranda Grande RH, Rodrigues Filho LE, de Oliveira Rocha R. Effect of cariogenic challenge on bond strength of adhesive systems to sound and demineralized primary and permanent enamel. J Adhes Dent. 2014;16(5):421-428.

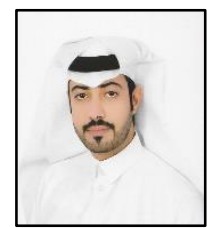

Dr. Mohammed S. Aldossary BDS, MClinDent

Specialist in Pediatric Dentistry,

General Directorate of Dentistry,

Ministry of Health, Riyadh, Saudi Arabia.

ORCID: 0000-0002-0380-7905. 